\title{
Erratum to: Survey of Clostridium botulinum toxins in Iranian traditional food products
}

\author{
Hamid Reza Tavakoli
}

Published online: 20 October 2009

(C) Springer-Verlag London Limited 2009

\section{Erratum to: Comp Clin Pathol}

DOI 10.1007/s00580-009-0865-0

Hedayat Hosseini, Mahzad Aghazadeh Meshgi, Ramin Khaksar, Marzieh Hosseini and Mansour Khakpour were listed as co-authors. However, they were not involved in writing the article and have requested that their names be removed. The only author of the paper is Dr. Hamid Reza Tavakoli.

The online version of the original article can be found under http://dx. doi.org/10.1007/s00580-009-0865-0.

H. R. Tavakoli $(\bowtie)$

Baqyatallah University of Medical Science,

Tehran, Iran

e-mail: hamid1346@yahoo.com 